\title{
Response Properties of Horizontal Cells in the Isolated Retina of Wild-Type and Pearl Mutant Mice
}

\author{
Hitoshi Suzuki ${ }^{1}$ and Lawrence H. Pinto \\ Department of Biological Sciences, Purdue University, West Lafayette, Indiana 47907
}

Intracellular recordings were made from axon bearing horizontal cells in isolated retinas (with retinal pigment epithelium removed) of normal and pearl mutant mice superfused with mammalian Ringer's solution. Cells were injected with Lucifer yellow and identified by their morphology and their response waveforms. On impalement, we measured a dark, resting voltage of 25-35 mV. All cells had similar spectral sensitivities that were consistent with the CIE scotopic relative spectral luminosity function. For stimuli of high irradiance, two types of responses could be distinguished, based on their waveform at stimulus offset. One consisted of a rapid and wavelength-dependent repolarization followed by a small, slow hyperpolarization. The other consisted of a large, long-lived, and wavelength-independent after-hyperpolarization. The former were recorded from the somatic end and the latter from the axon terminal arborization. The spatial distribution of sensitivity was measured in over 100 locations within the receptive field using small stimuli. The area within which sensitivity of the soma was within 0.1 $\log$ unit of the maximal sensitivity was larger than that of the soma dendritic field, but the sizes were nearly equal for the terminal arborization. No secondary maximum of sensitivity was noted over the dendritic field of the unimpaled part of the cell. For the terminal arborization, the half-saturating irradiance for diffuse $502 \mathrm{~nm}$ stimuli was about 180 photons $\mu \mathrm{m}^{-2} \mathrm{sec}^{-1}$, about one-tenth that for the soma. These values are in good agreement with those for cat and rabbit. For pearl mutant mice (in which the photoreceptor synapse is abnormal and the retinal sensitivity, measured using retinal ganglion cell responses, is subnormal in the intact animal but not in the isolated retina), the response characteristics, spectral sensitivity, and absolute sensitivity were indistinguishable from those found in wild-type mice. These latter results show that the normality of the responses of ganglion cells in isolated pearl retinas is not due to, e.g., decreases in signal transmission across the outer plexiform layer that are offiset by increases in transmission across a more proximal retinal layer. The results are also consistent with the retinal pigment epithelium being a site of expression of the pearl gene, but they do not preclude another site of expression in the retina.

The responses of mouse horizontal cells have not yet been studied, but there are a number of reasons for doing so. The mouse is the best-suited vertebrate animal for genetic studies, with over 500 named mutations available, 13 of which have been shown to affect the visual system in subtle ways that do not involve gross degeneration or generalized "neuromuscular" distur-

\footnotetext{
Received July 2, 1985; revised Sept. 6, 1985; accepted Sept. 10, 1985.

We wish to thank Drs. R. Dacheux, U. C. Dräger, A. Mariani, and R. Nelson for helpful discussions and for reading the manuscript. This work was supported by NIH Grants R01-EY01221, R01-EY02536, and R30-EY02723.

Correspondence should be addressed to Dr. Pinto.

Present address: Department of Physiology, Tohoku University School of Medicine, Sendai, Japan.

Copyright (c) 1986 Society for Neuroscience $0270-6474 / 86 / 041122-07 \$ 02.00 / 0$
}

bances (Balkema et al., 1984). For one of these mutations, pearl, the sensitivity of the retina and the synapse of the rod photoreceptor are affected in the dark-adapted condition. The stimulus illumination required to evoke a response of criterion amplitude from the retinal ganglion cell is greater than for wildtype in the intact, anesthetized animal (Balkema and Pinto, 1982), but is equal to that for wild-type in the isolated retina, from which the retinal pigment epithelium is removed (Balkema et al., 1983). In animals fixed by vascular perfusion, the ribbon lamellae of the rod synapses display attached bulbous thickenings, whereas the lamellae of retinas fixed after isolation from the retinal pigment epithelium do not display these thickenings (Williams et al., 1985a). Taken together, these results point to the retinal pigment epithelium as a site of expression of the pearl gene. However, recordings from horizontal cells would provide more direct evidence about the site and mechanisms of gene expression by (1) identifying the retinal layer that is affected in preparations in which the reduced sensitivity is expressed and (2) exploring the possibility that the normality of the responses of retinal ganglion cells in isolated pearl retinas results from offsetting changes in signal transmission across various retinal layers. We have begun to study the physiological properties of horizontal cells in the isolated retina preparation. This preparation permits control over electrode placement, allows receptive fields to be mapped with respect to retinal landmarks such as blood vessels and maintains the response characteristics of retinal ganglion cells in wild-type retinas nearly equal to those found in the intact animal (Balkema et al., 1983).

Horizontal cells of the mammalian retina may be axon-bearing or axonless. Some axon-bearing horizontal cells have a somatic end with thickened dendritic specializations and an axon of variable length that connects with a terminal arborization that has fine dendritic specializations (cat and rabbit: Boycott et al., 1978; Dacheux and Raviola, 1982; Dowling et al., 1966; Fisher and Boycott, 1974; Gallego, 1971; monkey: Gallego, 1976; Kolb, 1970). In the cat and the monkey, the terminal arborization has been shown to make synaptic contact only with rods, and the somatic end has been shown to make synaptic contact only with cones (Kolb, 1970, 1974).

Recordings have been made from both the terminal arborization and somatic end to compare the response amplitude, action spectrum, and response waveform. For large-area stimuli the plot of response amplitude vs log irradiance shows about one log unit greater responsiveness for the terminal arborization than for the somatic end (cat: Nelson et al., 1975; rabbit: Bloomfield and Miller, 1982; Dacheux and Raviola, 1982). In the cat, the action spectrum of horizontal cells shows a Purkinje shift on light adaptation (Steinberg, 1969a). The waveform of the responses elicited from the terminal arborization differs from that of the somatic end when studied with near-saturating stimuli. After stimulus offset the membrane of the terminal arborization remains hyperpolarized for $5-30 \mathrm{sec}$, while the membrane potential recorded from the somatic end returns rather 
quickly to near the dark resting value (Dacheux and Raviola, 1982; Nelson et al., 1976). Differences in the time course of the light response have been shown for stimuli of long and short wavelength (Dacheux and Raviola, 1982; Nelson et al., 1975, 1977). However, these physiological studies have not addressed the issue of the comparison of the anatomically determined dendritic field and physiologically determined receptive field for each of the two ends of the cell.

We have found that axon-bearing horizontal cells of the normal, wild-type mouse have morphology and response properties that are similar to those described for the cat and the rabbit. The occasional great stability that is possible in recording from the isolated mouse retina has made possible comparisons of the dendritic, axonal, and receptive fields of the same cell and study of response waveform and action spectrum in the same cell. In the isolated, superfused retina of the pearl mutant mouse, the response properties and morphology are indistinguishable from those of the normal, wild-type mouse.

\section{Materials and Methods}

Normal, wild-type animals were from the inbred C57BL/6J strain. The mutant animals were from the congenic $\mathrm{C} 57 \mathrm{BL} / 6 \mathrm{~J}$ pe/pe strain. The animals were maintained in a $12 \mathrm{hr}$ light $/ 12 \mathrm{hr}$ dark cycle, with temperature and humidity maintained according to the recommendations of the Jackson Laboratory (Heiniger and Dorey, 1980). The animals were between 2 and 9 months old. The parents of the animals were vaccinated against Sendai virus a week before breeding, and the experimental animals themselves were innoculated at weaning (normally 17$21 \mathrm{~d}$ old).

The experimental animal was dark-adapted 4-24 hr and then killed by cervical dislocation under dim red light. The remaining procedures employed infrared illumination and image converters. The eye was removed by evulsion; the cornea was slit; the lens was removed, and the scelera, choroid, and retinal pigment epithelium were torn in several places in order to produce an isolated retina. The blood vessels of the retina allowed it to be oriented reproducibly in a chamber $(0.3 \mathrm{ml})$ with a transparent bottom. This chamber was placed on the stage of a compound microscope equipped with a water-immersion objective $(40 \times$, 0.75 N.A.). Ringer's solution ( $120 \mathrm{~mm} \mathrm{NaCl}, 7.5 \mathrm{~mm} \mathrm{KCl}, 24 \mathrm{~mm}$ $\mathrm{NaHCO}_{3}, 0.6 \mathrm{mM} \mathrm{MgCl}, 1.9 \mathrm{~mm} \mathrm{CaCl}, 11 \mathrm{~mm}$ D-glucose, $2.8 \mathrm{~mm}$ HEPES, pH 7.4, $40 \mathrm{mmHg} \mathrm{PCO}_{2}, 600 \mathrm{mmHg} \mathrm{PO}_{2}, 36^{\circ} \mathrm{C}, 290 \mathrm{mOs} /$ $\mathrm{kg}$ ) flowed through the chamber at $2 \mathrm{ml} / \mathrm{min}$.

The stimulus (502 $\mathrm{nm}$ unless otherwise shown; maximum irradiance $1.45 \times 10^{6}$ photons $\mu \mathrm{m}^{-2} \mathrm{sec}^{-1}$ ) was delivered through the microscope condenser. Responses were recorded directly by a digital computer, which also controlled stimulus timing.

The fluorescent tracer Lucifer yellow (Stewart, 1978) was injected by pressure using the methods of Oakley and Pinto (1983). We found that an clectrolyte consisting of $4 \%$ Lucifer yellow and $250 \mathrm{~mm} \mathrm{LiCl}$ produced the best compromise between low pipette impedance and lack of damage to the injected cell due to influx of water following an increase of intracellular osmolality resulting from injection of highly concentrated electrolytes. After injecting a cell and measuring its receptive field, the receptive field map was aligned with a tracing of the retinal blood vessels. The retina was then dehydrated between a microscope slide and a coverslip. The dehydrated retina was infiltrated with monomer of glycol methacrylate (Stewart, 1978) and then viewed with an epifluorescence microscope ( $40 \times$ oil immersion objective, $0.6-1.0$ N.A.); the outline of the injected cell was traced, and a second tracing of the retinal vessels was superimposed on the outline of the cell. The first and second tracings of the vessels were then superimposed in order to bring the tracing of the dendritic field into register with the receptive field map.

We sclccted for study only those cells that met the following criteria: on impalement the dark resting membrane voltage (uncorrected for differences in tip potential inside vs outside the cell) was more negative than $-25 \mathrm{mV}$; the dark resting membrane voltage did not change by more than $2 \mathrm{mV}$ during the time of study; and a full-field stimulus of nearly saturating amplitude (approximately $5 \times 10^{3}$ photons $\mu \mathrm{m}^{-2} \mathrm{sec}^{-1}$, $200 \mathrm{mS}$ duration, $502 \mathrm{~nm}$ ) evoked a response of at least $10 \mathrm{mV}$ peak amplitude.

The action spectrum was measured in at least one of three ways: (1) The response amplitude vs irradiance function was determined for each wavelength studied; a function given by equation 1 (see Results) was fitted to the experimental data, and the value of the irradiance for a half-maximal response $(\sigma)$ was determined for each wavelength. Differences between the values obtained for $\sigma$ at various wavelengths were used as an index of relative scnsitivity. (2) For each wavelength the irradiance required to evoke a response of a criterion amplitude (usually $4 \mathrm{mV}$ ) was measured, and the inverse of the irradiance plotted against wavelength. (3) The response amplitude vs irradiance function was determined for only one wavelength. Next, stimuli of various wavelengths but equal CIE scotopic effectiveness were presented. For each response, interpolation along the amplitude vs irradiance function was used to determine the relative sensitivity of the cell.

\section{Results}

\section{Wild-type mice}

\section{Morphology of labeled cells}

Each of the 37 labeled cells had a fine axon-like process connected to either one or two heavily labeled elements. The overall morphology of these cells closely resembled that described for early postnatal horizontal cells of the mouse (Ramón y Cajal, 1980). When two elements were labeled, one of them was always more heavily labeled. One of these elements appeared similar to the soma of the B-type horizontal cell of the cat (Boycott et al., 1978; Dowling et al., 1966; Fisher and Boycott, 1974) and the sumatic end of the axon-bearing horizontal cell of the rabbit (Dacheux and Raviola, 1982; Dowling et al., 1966), while the other element appeared similar to the terminal arborization of these previously described cells (Fig. 1). Most cells were located less than $600 \mu \mathrm{m}$ from the optic disk. In these cells the soma had a diameter of 5-8 $\mu \mathrm{m}$, and from four to seven main processes (0.5-1 $\mu \mathrm{m}$ diameter at their origin) radiating from the soma. The outline of the area that these processes covered was roughly circular (about $50 \mu \mathrm{m}$ diameter). The axon of these cells had a length between 50 and $230 \mu \mathrm{m}$. In most of the cells it could be seen originating from the soma itself, although in three cells the images of the axon and one of the processes were superimposed, obscuring the origin of the axon. On the other hand, the terminal arborization of the injected cells had a single thick (2-3 $\mu \mathrm{m}$ diameter) process from which 8-15 finer processes (of about 0.5 $\mu \mathrm{m}$ diameter) radiatcd. These finer processes were wavier than those of the soma, and the outline of the area that they covered was larger (from 100 to $150 \mu \mathrm{m}$ diameter) than that of the soma. Either the terminal arborization was more heavily labeled or it alone was labeled in $80 \%$ of the labeled cells.

\section{Response properties}

Full-field stimuli of low irradiance evoked responses that consisted of a monotonic hyperpolarization at onset and a monotonic return of membrane voltage to the dark resting value at offset from both the soma and the terminal arborization (Fig. 2). Full-field stimuli of intermediate irradiance evoked a transient undershoot of membrane voltage, followed by a return of membrane voltage to a steady hyperpolarized value during illumination. The transient undershoot was more pronounced in the responses recorded from the terminal arborization. Fullfield stimuli of saturating amplitude evoked a steady hyperpolarization during illumination, but after offset the waveform differed markedly for the two recording sites. The membrane potential of the terminal arborization decayed very slowly to the dark resting value. This slower hyperpolarizing afterpotential was similar to the "rod after-effect" in S-potentials of cat (Nelson, 1977; Steinberg, 1969b) and rabbit (Bloomfield and Miller, 1982; Dacheux and Raviola, 1982). The membrane potential of the soma quickly and transiently returned to near the dark resting value, then became more negative and finally decayed to the dark resting value.

The plot of response amplitude vs irradiance for stimuli of 450,502 , and $580 \mathrm{~nm}$ wavelength (Fig. 3) could be fitted by an equation of the form 


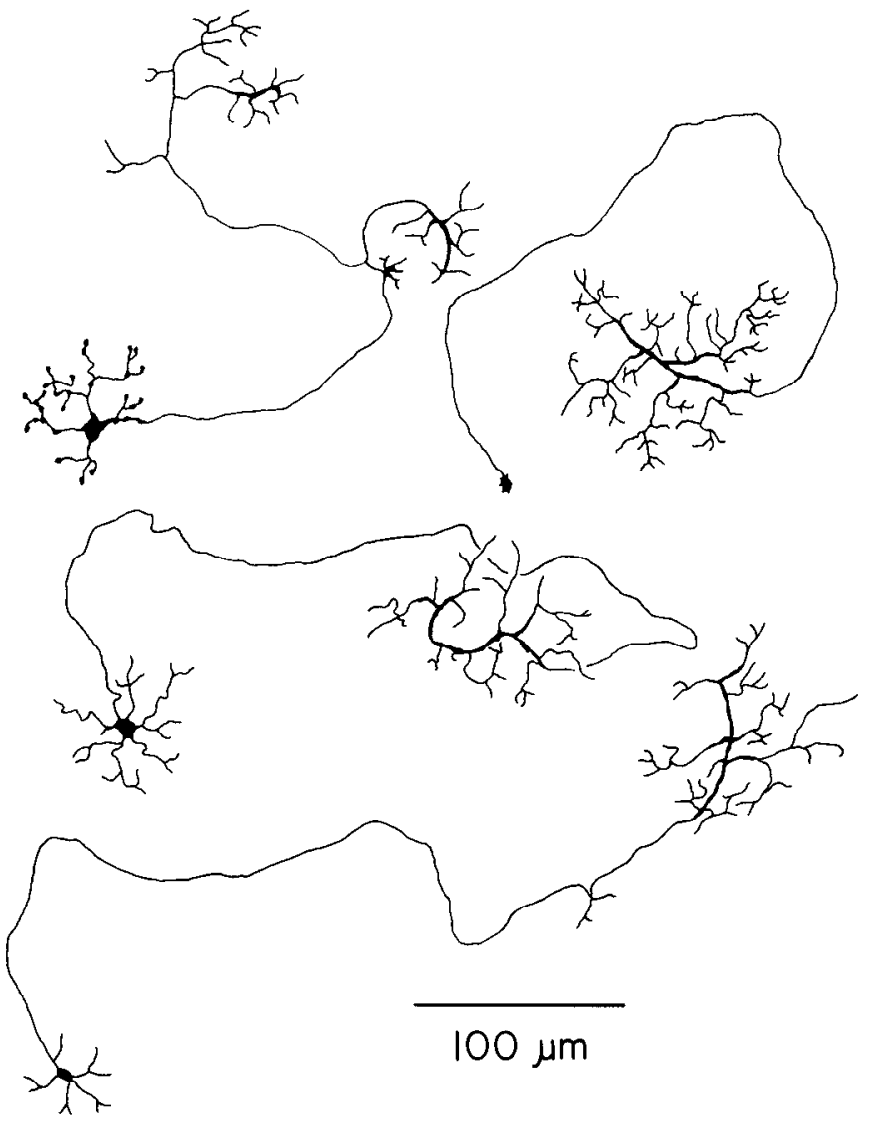

Figure 1. Camera lucida tracings of horizontal cells injected with Lucifer yellow in the wild-type retina. The details of the aggregation of terminations are not drawn.

$$
V / V_{\max }=I^{n} /\left(I^{n}+\sigma^{n}\right),
$$

where $V$ is the response amplitude measured at the time of peak hyperpolarization; $V_{\max }$, the maximal response amplitude; $I$, the stimulus irradiance; $\sigma$, the irradiance for half-maximal response; and $n=0.96$. The value of $\sigma$, measured with $502 \mathrm{~nm}$ stimuli, was $0.84 \log$ units lower for the terminal arborization than for the soma (Table 1). The absolute value for $\sigma$ (about 180 photons $\mu \mathrm{m}^{-2} \mathrm{sec}^{-1}$ for the terminal arborization) agreed well with the values previously obtained for the rod component of the response of the soma of the cat (Nelson, 1977) and plots of response amplitude vs illumination for the rabbit (Raviola and Dacheux, 1983).
A

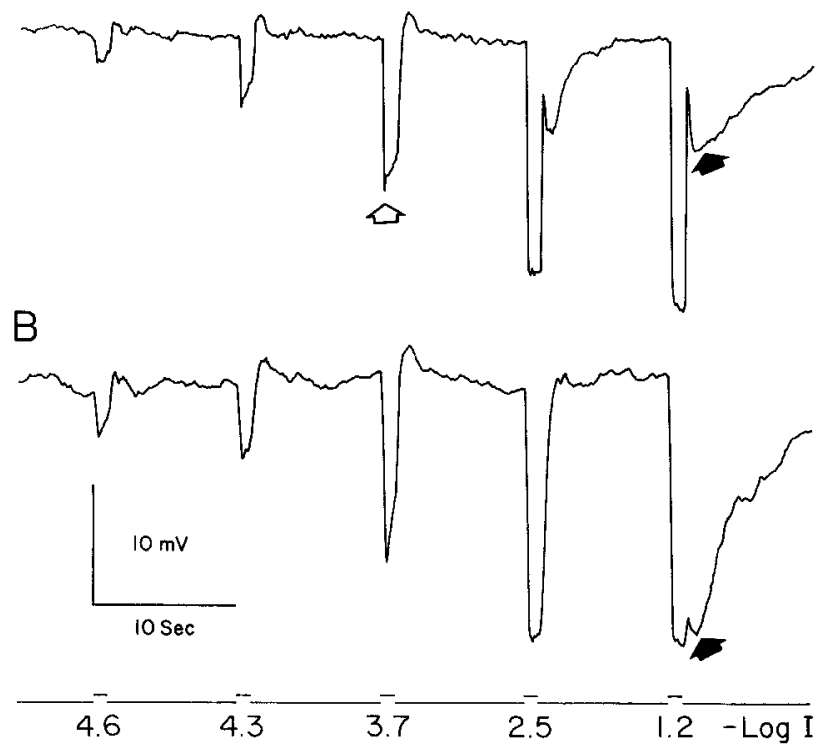

Figure 2. Responses evoked by full-field stimuli (lowest record, attenuation indicated by numerals) from somatic end $(A)$ and terminal arborization $(B)$. Note the more pronounced after-hyperpolarization that follows a stimulus of high irradiance for the terminal arborization (compare closed arrows) and the transient hyperpolarizing undershoot for a stimulus of intermediate irradiance (indicated for somatic end by open arrow). Wild-type retina.

\section{Comparison of receptive field and dendritic field}

Preliminary measurements showed many receptive fields to have elliptical shape. Therefore, the following method was used to determine the shape of the receptive field, rather than a more convenient method that depends on circular symmetry (see Lamb, 1976).

For 10 impalements it was possible to measure the spatial distribution of relative sensitivity in as many as 100 locations within the receptive field. This was done by holding a small (60 $\mu \mathrm{m}$ diameter) stimulus fixed in the most sensitive part of the receptive field and determining the function of response amplitude vs irradiance. The stimulus irradiance was then adjusted to a value along the rising portion of the function, and the stimulus was presented in each of many locations separated by $100 \mu \mathrm{m}$. Interpolation along the response vs irradiance function was performed to determine relative sensitivity in each location. The two-dimensional plot of sensitivity (Fig. 4) was used to draw equal-sensitivity contours.

Table 1. Comparison of properties of wild-type and mutant cells

\begin{tabular}{llllll} 
& $+/+$ Strain & & & pe/pe Strain & \\
\cline { 2 - 3 } & Soma & $\begin{array}{c}\text { Terminal } \\
\text { arborization }\end{array}$ & & Soma & $\begin{array}{c}\text { Terminal } \\
\text { arborization }\end{array}$ \\
\hline$\sigma$ & $11.1 \pm 2.2 \times 10^{2}$ & $1.8 \pm 0.2 \times 10^{2}$ & & $7.38 \times 10^{2^{a}}$ & $1.74 \pm 0.2 \times 10^{2}$ \\
$\bar{d}$ & $360 \pm 8$ & $389 \pm 40$ & - & $388 \pm 15$ \\
& $(125 \pm 18)$ & $(160 \pm 23)$ & & $(171 \pm 26)$ \\
$\lambda_{\max }$ & $510 \mathrm{~nm}$ & $510 \mathrm{~nm}$ & $510 \mathrm{~nm}$ & $510 \mathrm{~nm}$
\end{tabular}

$\sigma$ is irradiance for half-maximal response, $502 \mathrm{~nm}$, photons $\mu \mathrm{m}^{-2} \sec ^{-1} . d$ is geometric mean of major and minor axes of receptive field $(\mu \mathrm{m}) ; 0.1 \log$ unit area; $1 \log$ unit area shown in parentheses.

- Values given are means \pm SEM single measurement. 


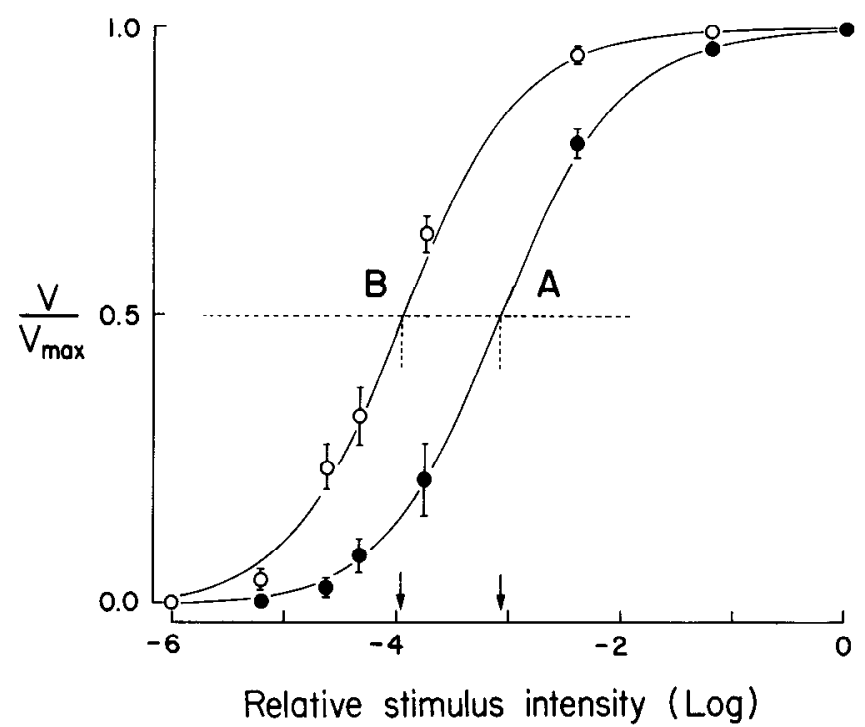

Figure 3. Plot of normalized peak response amplitude vs irradiance of full-field stimuli for terminal arborization (open symbols) and somatic end (filled symbols). Data are taken from 28 terminal arborizations and 7 somatic ends. Stimulus wavelength was $502 \mathrm{~nm}$ in all cases. Bars represent the SEM. Wild-type retina.

There are limitations to the accuracy and precision of the technique. The first arises from the finite size $(60 \mu \mathrm{m})$ of the stimulus spot, which would cause an underestimation of the gradient of sensitivity in some parts of the insensitive region of the receptive field (Fig. 5), but would not have affected the contours in the more sensitive part of the receptive field (Fig. 6). A second limitation arises from variability in the size of the response to a given stimulus. We measured this variability in five cells and transformed the response variability into equivalent variability of the stimulus by using the plot of response amplitude vs irradiance. The range of equivalent stimulus variability was $0.15 \log$ units $(0.06 \log$ units SD). For the most sensitive parts of the receptive field (Fig. 6), this variability would cause an uncertainty in the location of a receptive field contour of $30 \mu \mathrm{m}$.

The receptive ficld arca within which scnsitivity cxcceded 0.1 $\log$ unit less than the maximum sensitivity (hereafter called the $0.1 \log$ unit area) was approximately circular for the terminal arborization (150 $\mu \mathrm{m}$ diameter) and elliptical for the somatic end (Fig. 6). Moreover, the minor axis of the elliptical area of the somatic end (Fig. 6A) was approximately half as long as the diameter of the circular area of the terminal arborization (Fig. $6 B$ ). The rate of decay of sensitivity along a radius of the receptive field was between 0.2 and $0.4 \log$ units per $100 \mu \mathrm{m}$ for both somatic end and terminal arborization within the $1.0 \mathrm{log}$ unit area. Outside of the $1.0 \mathrm{log}$ unit area the sensitivity fell much more slowly for the somatic end than for the terminal arborization. The long axis of the $0.1 \log$ unit area of the terminal arborization bore no fixed relationship to the long axis of either the $1.0 \mathrm{log}$ unit or $2.0 \mathrm{log}$ unit area. The $2 \log$ unit area was larger for the somatic end than that for the terminal arborization (Fig. 5).

The location of the optic disk was noted for six terminal arborizations. For these cells the orientation of the long axis of the receptive field was determined. The orientation of the line connecting the receptive field middle with the optic disk was also noted, and compared with the orientation of the long axis of the $1.0 \log$ unit area (Fig. 5) of the receptive field. These lines were found to diverge by no more than $11^{\circ}$ (mean $3.8^{\circ} \pm 5.7^{\circ}$ $\mathrm{SE})$, showing that the receptive fields were oriented radially
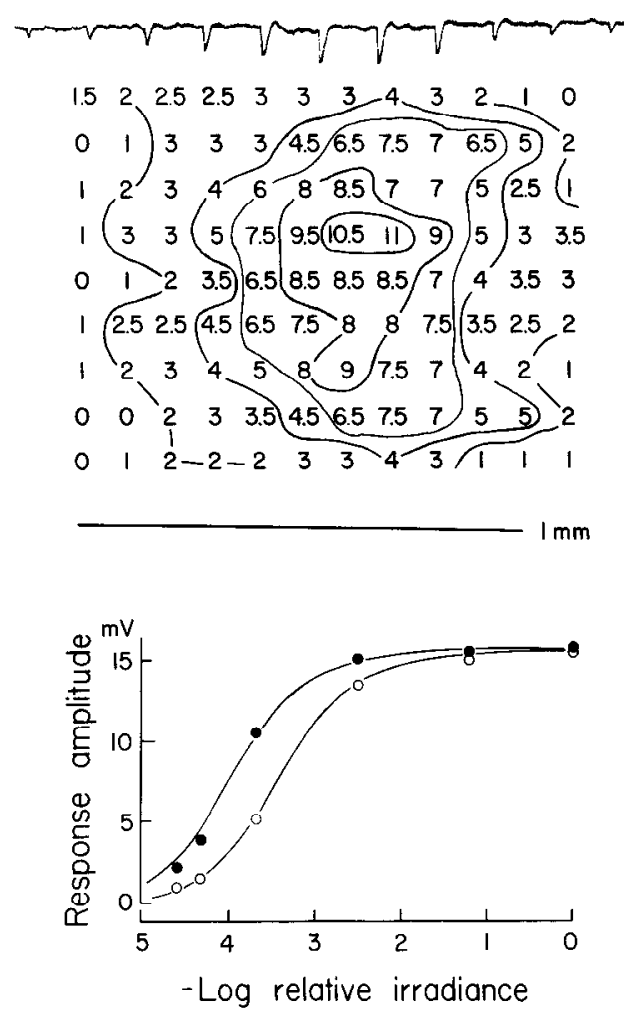

Figure 4. Determination of spatial distribution of sensitivity with high resolution. Upper tracing is record of responses to each of 11 stimuli ( $3 \times 10^{2}$ photons $\mu \mathrm{m}^{-2} \mathrm{sec}^{-1}$ irradiance, $60 \mu \mathrm{m}$ diameter, $502 \mathrm{~nm}, 100$ msec in duration). These responses were evoked by stimuli presented in each of 11 of the 12 locations along the fourth from the upper row (the response to the left-most position is omitted). The peak response amplitudes are given by the numerals in this row. The other numerals are the similarly obtained data for eight other rows. Equal-amplitude contours are superimposed on the numerals. Calibration bar (below numerals), $1 \mathrm{~mm}$. The lowest graph shows maximum response amplitude vs irradiance, obtained with a stimulus located in the most sensitive part of the receptive field. A curve of similar shape, but shifted to higher irradiance, was obtained for another location $(400 \mu \mathrm{m}$ to the left of the most sensitive position). Interpolation along such curves was performed to obtain the contours shown in Figures 5 and 6 . Wild-type retina.

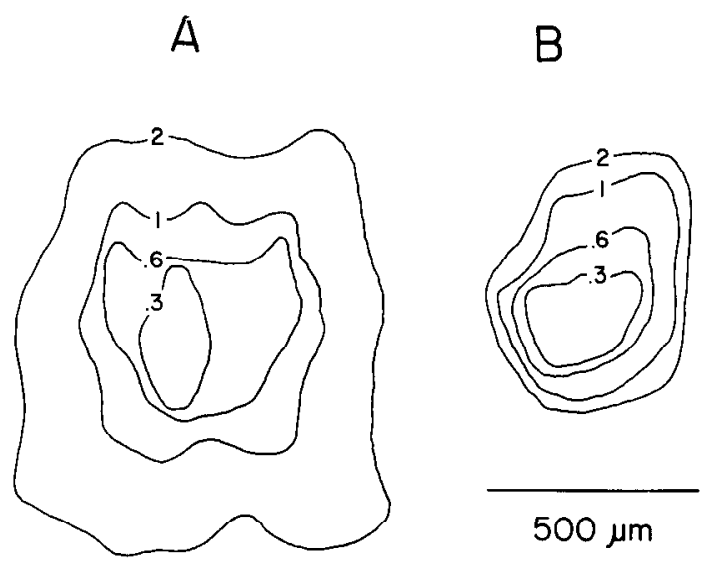

Figure 5. Distribution of relative sensitivity for the somatic end $(A)$ and terminal arborization $(B)$. Regions of low relative sensitivity are shown. Note the larger receptive field size and more gradual decay of sensitivity with the distance from the receptive field middle for the somatic end. Wild-type retina. 


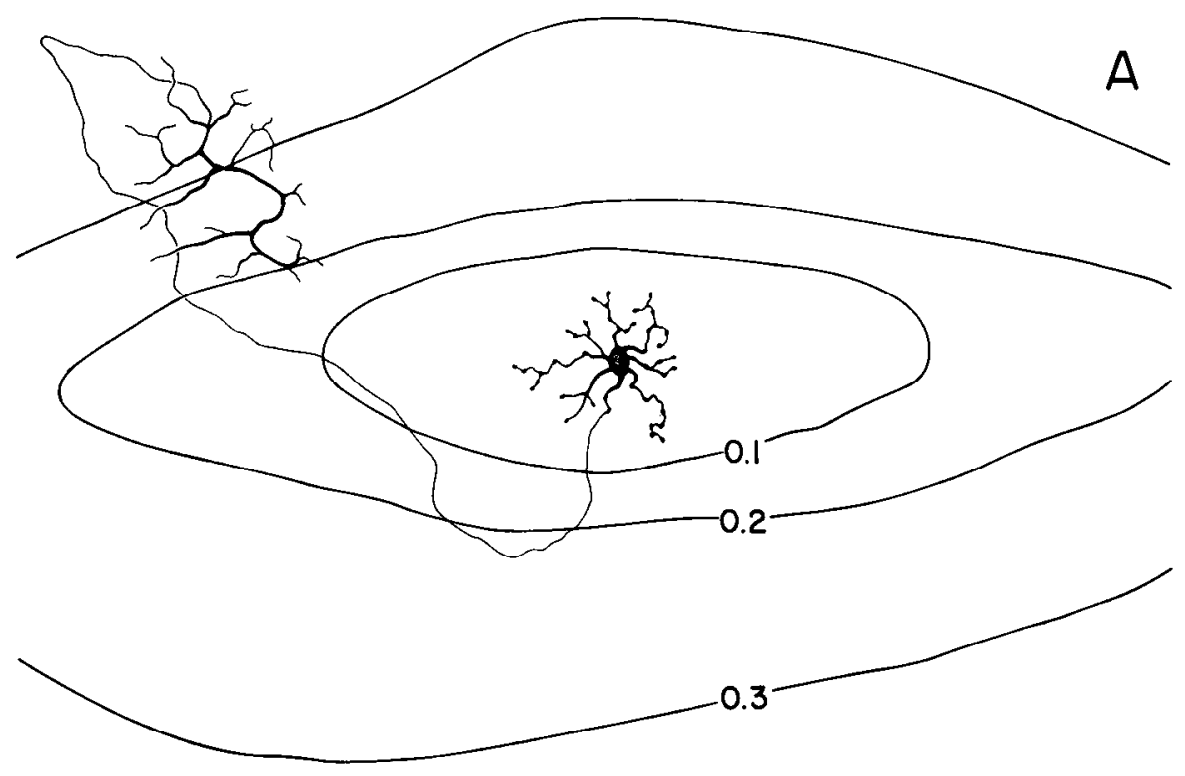

Figure 6. Distribution of relative sensitivity superimposed on the reconstruction of the Lucifer yellow image for the somatic end $(A)$ and terminal arborization $(B)$. Note that the size of the $0.1 \log$ unit receptive field is approximately equal to that of the dendritic field for the terminal arborization, but that the $0.1 \log$ unit receptive field of the somatic end is considerably larger than the dendritic field. Wild-type retina.

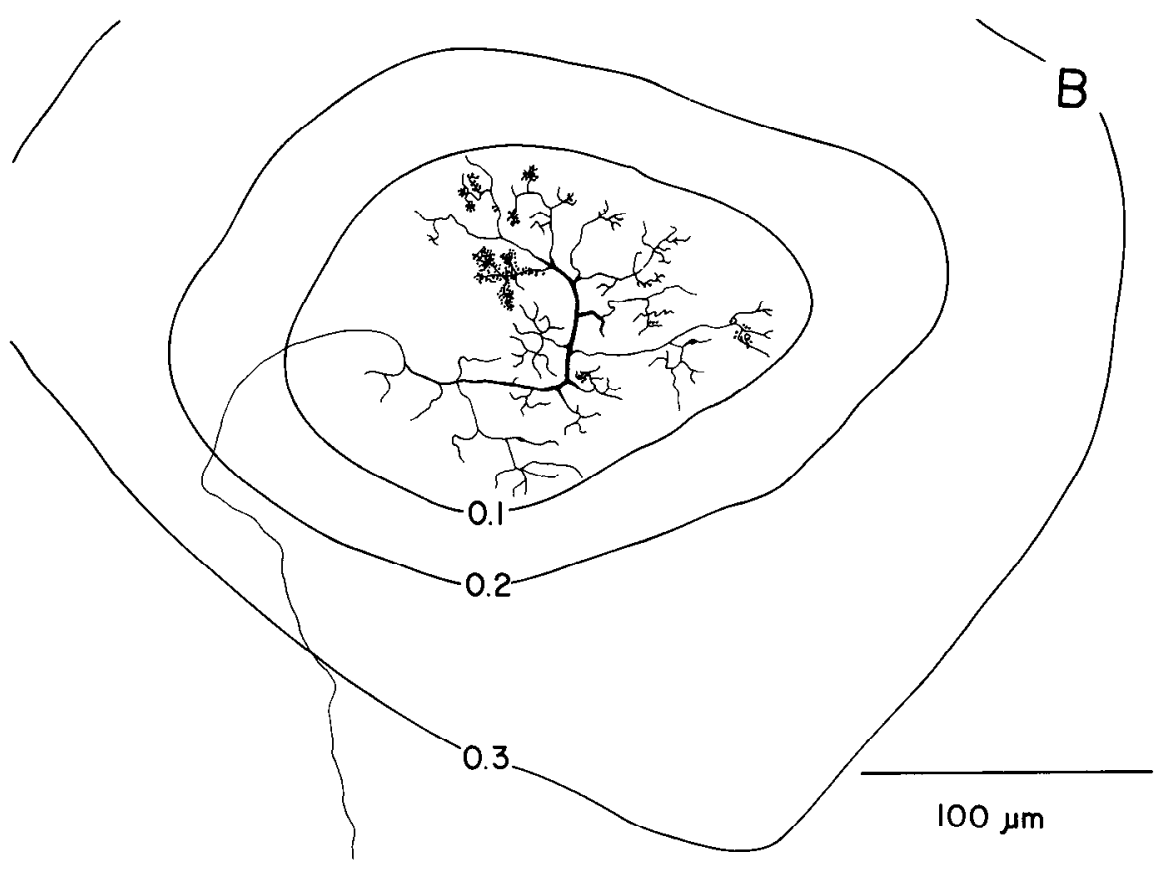

about the optic disk. However, no such orientation was found for the more sensitive contours of the receptive field of the terminal arborization or for any contour of the somatic end. The receptive field orientation found for the terminal arborization is similar to that shown for the orientation bias of the receptive field of retinal ganglion cells in the cat: The grating that evokes the maximal ganglion cell response tends to lie parallel to the line joining the cell with the area centralis (Levick and Thibos, 1982).

The dendritic field of the terminal arborization nearly filled the $0.1 \log$ unit area (Fig. $6 \mathrm{~B}$ ), whereas the dendritic field of the somatic end was considerably smaller than the $0.1 \mathrm{log}$ unit area. For neither recording site did a secondary maximum of sensitivity occur at the place in the retina where the unimpaled part of the cell was located.

\section{Spectral sensitivity}

We measured the action spectrum of both the soma and the terminal arborization in the dark-adapted condition using the responses to dim stimuli. The spectra were plotted and a Dartnall nomogram (Dartnall, 1953) was fitted to each plot. The wavelength of maximal sensitivity was about $510 \mathrm{~nm}$ for each plot (Fig. 7). However, when stimuli of irradiance sufficient to evoke responses of between half-maximal amplitude and about $90 \%$ of maximal amplitude were applied in the dark-adapted condition (Fig. 7), differences in the response waveform of the somatic end were evident for stimuli of long and short wavelength. After offset of a long-wavelength stimulus, the membrane voltage returned more quickly to its dark resting value than after offset of a short-wavelength stimulus. However, such differences 
were not evident in recordings from the terminal arborization. This difference in time course is consistent with the existence of more than one spectral mechanism for the responses of the somatic end.

\section{Pearl mutant mice}

Recordings were obtained from a total of 14 cells in the pearl mutant retina. Intracellularly injected label was observed in seven of the cells (one soma and six axon terminals). The morphology of these injected cells could not be distinguished from that of the cells in wild-type retinas. Furthermore, no differences between the waveform of the responses, the sensitivity, the receptive field size, or the action spectrum for these cells in the two genotypes could be detected (Table 1).

\section{Discussion}

Axon-bearing horizontal cells of the mouse have anatomical and physiological characteristics that are similar to those of the cat and the rabbit. Moreover, the physiological differences in spectral properties between the somatic end and the terminal arborization in the mouse are consistent with the differences in the synaptic inputs to these parts of the cell that have been reported for the cat and rabbit. Detailed mapping of the receptive field and comparison with the dendritic field confirms previous reports of the independence of signal processing in the two ends of the cell. The responses of the isolated retinas of pearl mutant mice were indistinguishable from those of wildtype mice. This result is consistent with the retinal pigment epithelium as a site of gene expression and with the restoration of the responsiveness of the retinal ganglion cells (Balkema et al., 1983) and of the morphology of the ribbon lamellae of the photoreceptors (Williams et al., 1985a) that have been demonstrated in the isolated retina.

The action spectrum of the somatic end did not show the relatively high sensitivity for long-wavelength stimuli that has been shown for the cat (Nelson, 1975, 1977). This may be a consequence of the lower percentage ( $2 \%$ uniformly distributed) of cones found in the mouse retina (Carter-Dawson and LaVail, 1979) than in those regions of the retinas of the cat (Steinberg et al., 1973) or the rabbit (Hughes, 1971) that contain the horizontal cells that have been studied. It has been shown that the somatic end in the cat makes synaptic contact only with cones (Kolb, 1974), and that the rod inputs probably reach the somatic cnd via concs (Nelson, 1975, 1977) through gap junctions between rods and cones (Raviola and Gilula, 1973), but not via the axon terminal. Perhaps such cone-to-rod coupling is weaker in the mouse than in other species. Our high-resolution measurements of the sensitivity distribution show that there is no region of elevated sensitivity located over the terminal arborization. These results support the conclusions of earlier workers that rod signals do not travel via the axonal process.

We found the $0.1 \mathrm{log}$ unit receptive field of the somatic end to be several times larger than its dendritic field. This larger receptive field for the somatic end is consistent with previous measurements of receptive field size (Dacheux and Raviola, 1982), but we do not know the mechanism by which signals arrive at the soma.

In common with the cat and the rabbit (Bloomfield and Miller, 1982; Dacheux and Raviola, 1982; Nelson et al., 1975), the sensitivity of the terminal arborization of mouse horizontal cells is greater than that of the somatic end. The resolution of our light microscopy did not allow us to identify or count the number of photoreceptors with which these two parts of the cell made contact. However, it has been shown in the cat and monkey that the more sensitive terminal arborization receives synaptic inputs from rods, while the somatic end receives synaptic input from cones (Kolb, 1970, 1974). Perhaps this difference is the basis for the sensitivity difference in the mouse.

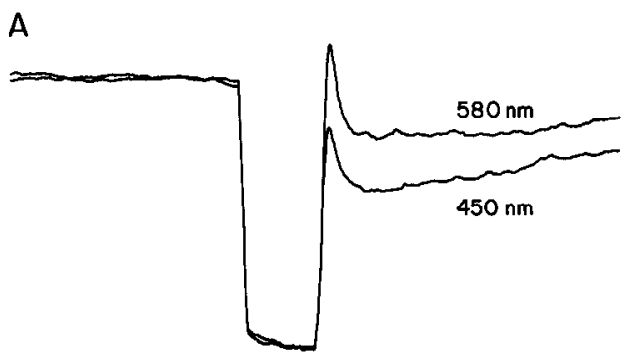

B

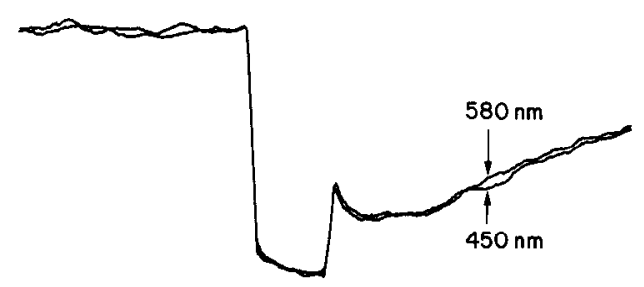

C

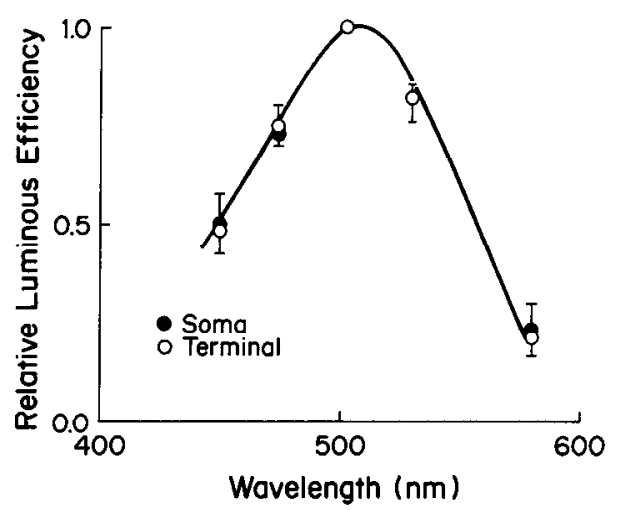

Figure 7. Responses from somatic end $(A)$ and terminal arborization $(B)$ to nonsaturating stimuli of two different wavelengths (numeral indicated). Note that for both wavelengths the responses had the same amplitude while the stimulus was on, but that for $10 \mathrm{sec}$ after stimulus offset the somatic end only was more hyperpolarized for the shorterwavelength stimulus. $C$, Action spectra for terminal arborization (open symbols) and somatic end (closed symbols). Data were taken from 29 terminal arborizations and 9 somatic ends in dark-adapted retinas. Bars represent SEM. The line drawn is the Dartnall nomogram $\left(\lambda_{\max }=510\right.$ $\mathrm{nm})$. Wild-type retina.

Each of the 37 cells from which dye was recovered clearly showed an axonal process leading from the heavily labeled, impaled part. In most cases the less heavily labeled, unimpaled part was also seen. However, in no case did we find an injected cell without an axonal process. We do not think that this is because such cells do not exist. Rapid Golgi studies (A. Mariani, personal communication) and labeling with an antibody directed against neurofilaments (Dräger, 1983) demonstrated cells in the outer margin of the inner nuclear layer of mice that have the overall morphology of neurofilament-rich (Fisher and Boycott, 1974) axonless (A-type) horizontal cells found in other species (see Boycott et al., 1978; Kolb, 1974). We think it is unlikely that we simply failed to recover the label from such cells after injection because we recovered as many as $70 \%$ of injected cells in some experiments, and many of the horizontal cells in the mouse are of the axonless type (see Dräger, 1983; Dräger et al., 1984). We also think it is unlikely that impalements of axonless horizontal cells were abandoned because they failed to meet our minimum-amplitude criteria (Material and Methods). The amplitude reported for these cells in other species is not significantly less than for axon-bearing horizontal cells 
(Bloomfield and Miller, 1982; Dacheux and Raviola, 1982; Nelson, 1977). We experienced facile impalement of axon terminals and difficult impalement of somatic ends. Perhaps axonless horizontal cells of the mouse are simply less amenable to penetration than the two major parts of the axon-bearing horizontal cell.

Pearl mutant mice have been demonstrated to have reduced retinal sensitivity when studied using the responses of retinal ganglion cells in the intact, anesthetized preparation (Balkema and Pinto, 1982), but not in the isolated retina, from which the retinal pigment epithelium has been removed (Balkema et al., 1983). Moreover, bulbous thickenings are found attached to the ribbon lamella of the rod photoreceptors of pearl mutants that are fixed in situ, but not in the isolated retina (Williams et al., 1985a). Thus, our present finding that the responses of pearl horizontal cells are normal in the isolated retina preparation is consistent with previous anatomical and physiological results that point to the retinal pigment epithelium (Williams et al., $1985 \mathrm{~b}$ ) as a site of gene expression. However, the present results do not preclude the possibility of another site of gene expression in the retina. Indeed, preliminary results (Suzuki and Pinto, 1985 ) indicate that the responses of both retinal ganglion cells and horizontal cells in the isolated retina preparation of pearl mutants are affected by low ( $5 \mathrm{nM}$ ) concentrations of somatostatin-14 in the bathing medium, whereas the responses of these cells in wild-type retinas are not affected.

It follows from the present results that signal transmission to the horizontal cells is probably normal for pearl mutants in the isolated retina preparation. Thus, it is unlikely that the normal retinal sensitivity measured using the responses of retinal ganglion cells (Balkema et al., 1983) in the isolated retina is due to a decrease in signal transmission across the outer plexiform layer that is offset by an increase in signal transmission in a more proximal layer.

In summary, horizontal cells of the mouse have properties that are quite similar to those of cat and rabbit, and they can be recorded from with remarkable stability. Mice have the advantage of ready availability of inbred strains, short gestation time $(21 \mathrm{~d})$, and the opportunity for genetic manipulation (Balkema et al., 1984; Green, 1975) and immunological analysis (Dräger, 1983; Dräger et al., 1984). Thus, mice ought to serve well as models for studying the physiology, genetics, and ontogeny of the outer plexiform layer.

\section{References}

Balkema, G. W., Jr., and L. H. Pinto (1982) Electrophysiology of retinal ganglion in the mouse: A study of a normally pigmented mouse and a congenic hypopigmentation mutant, Pearl. J. Neurophysiol. 48: 968-980.

Balkema, G. W., Jr., N. J. Mangini, and L. H. Pinto (1983) Discrete visual defects in pearl mutant mice. Science 219 : 1085-1087.

Balkema, G. W., Jr., N. J. Mangini, L. H. Pinto, and J. W. Vanable, Jr. (1984) Visually evoked eye movements in mouse mutants and inbred strains. Invest. Ophthalmol. Vis. Sci. 25: 795-800.

Bloomfield, S. A., and R. F. Miller (1982) A physiological and morphological study of the horizontal cell types of the rabbit retina. J. Comp. Neurol. 208: 288-303.

Boycott, B. B., L. Peichl, and H. Wässle (1978) Morphological types of horizontal cell in the retina of the domestic cat. Proc. R. Soc. Lond. [Biol.] 203: 229-245.

Carter-Dawson, L. D., and M. M. LaVail (1979) Rods and cones in the mouse retina. J. Comp. Neurol. 188: 245-265.

Dacheux, R. F., and E. Raviola (1982) Horizontal cells in the retina of the rabbit. J. Neurosci. 2: 1486-1493.

Dartnall, H. J. A. (1953) The interpretation of spectral sensitivity curves. Br. Med. Bull. 9: 24-30.

Dowling, J. E., J. E. Brown, and D. Major (1966) Synapses of horizontal cells in rabbit and cat retina. Science 153: 1639-1641.
Dräger, U. C. (1983) Coexistence of neurofilaments and vimentin in a neurone of adult mouse retina. Nature 303: 169-172.

Dräger, U. C., D. L. Edwards, and C. J. Barnstable (1984) Antibodies against filamentous components in discrete cell types of the mouse retina. J. Neurosci. 4: 2025-2042.

Fisher, S. K., and B. B. Boycott (1974) Synaptic organizations made by horizontal cells within the outer plexiform layer of the cat and the rabbit. Proc. R. Soc. Lond. [Biol.] 186: 317-331.

Gallego, A. (1971) Horizontal amacrine cells in the mammal's retina. Vis. Res. Suppl. 2: 33-50.

Green, M. C. (1975) Mutant genes and linkages. In Biology of the Laboratory Mouse, E. L. Green, ed., pp. 87-150, Dover, New York.

Heiniger, N. J., and J. J. Dorey (1980) Handbook of Genetically Standardized Mice, pp. 9.15-9.16, The Jackson Laboratory, Bar Harbor, ME.

Hughes, A. (1971) Topographical relationships between the anatomy and physiology of the rabbit visual system. Doc. Ophthal. 30: 33159.

Kolb, H. (1970) Organization of the outer plexiform layers of the primate retina: Electron microscopy of Golgi impregnated cells. Phil. Trans. R. Soc. Lond. [Biol.] 258: 261-283.

Kolb, H. (1974) The connections between horizontal cells and photoreceptors in the retina the cat: Electron microscopy of Golgi preparations. J. Comp. Neurol. 155: 1-14.

Lamb, T. (1976) Spatial properties of horizontal cell responses in the turtle retina. J. Physiol. (Lond.) 263: 239-255.

Levick, W. R., and L. N. Thibos (1982) Analysis of orientation bias in cat retina. J. Physiol. (Lond.) 329: 243-261.

Nelson, R. (1977) Cat cones have rod input: A comparison of the response properties of cones and horizontal cell bodies in the retina of the cat. J. Comp. Neurol. 172: 109-136.

Nelson, R., A. V. Lützow, H. Kolb, and P. Gouras (1975) Horizontal cells. Science 189: 137-139.

Nelson, R., H. Kolb, E. V. Famiglietti, and P. Gouras (1976) Neural responses in the rod and cone systems of the cat retina: Intracellular records and procion stain. Invest. Ophthalmol. 15: 946-953.

Oakley, B. II, and L. H. Pinto (1983) Modulation of membrane conductance in rods of Bufo marinus by intracellular calcium ion. $\mathrm{J}$. Physiol. (Lond.) 339: 273-298.

Ramón y Cajal, S. (1980) Studies on Vertebrate Neurogenesis, L. Guth, trans., p. 389, Thomas, Springfield, IL.

Raviola, E., and R. F. Dacheux (1983) Variations in structure and response properties of horizontal cells in the retina of the rabbit. Vis. Res. 23: 1221-1227.

Raviola, E., and N. B. Gilula (1973) Gap junctions between photoreceptor cells in the vertebrate retina. Proc. Natl. Acad. Sci. USA 70: 1677-1681.

Steinberg, R. H. (1969a) Rod and cone contributions to S-potentials from the cat retina. Vis. Res. 9: 1319-1329.

Steinberg, R. H. (1969b) The rod after effect in S-potentials from the cat retina. Vis. Res. 9: 1345-1355.

Steinberg, R. H. (1971) Incremental responses to light recorded from pigment epithelial cells and horizontal cells of the cat retina. J. Physiol. (Lond.) 217: 93-110.

Steinberg, R. H., M. Reid, and P. L. Lacy (1973) The distribution of rods and cones in the retina of the cat (Felis domesticus). J. Comp. Neurol. 148: 229-248.

Stewart, W. W. (1978) Functional connections between cells as revealed by dye-coupling with a highly fluorescent naphthalimide tracer. Cell 14: 741-759.

Suzuki, H., and L. H. Pinto (1985) The pearl mutation induces hypersensitivity of the retina to somatostatin-14. Soc. Neurosci. Abstr. 11: 12.

Williams, M. A., J. Gehrson, L. J. Fisher, and L. H. Pinto (1985a) Synaptic lamellae of the photoreceptors of pearl and wild-type mice. Invest. Ophthalmol. Vis. Sci. 26: 992-1001.

Williams, M. A., L. H. Pinto, and J. Gehrson (1985b) The retinal pigment epithelium of wild-type (C57BL/6J $+/+$ ) and pearl mutant (C57Bl/6J pe/pe) mice. Invest. Ophthalmol. Vis. Sci. 26: 657-669. 